\title{
Development and Evaluation of a Novel Pellet-Based Tablet System for Potential Colon Delivery of Budesonide
}

\author{
Jaleh Varshosaz, ${ }^{1}$ Jaber Emami, ${ }^{1}$ Naser Tavakoli, ${ }^{1}$ Mohsen Minaiyan, ${ }^{2}$ Nakisa Rahmani, ${ }^{1}$ \\ and Farid Dorkoosh ${ }^{3}$
}

${ }^{1}$ Department of Pharmaceutics, Faculty of Pharmacy and Novel Drug Delivery Systems Research Center,
Isfahan University of Medical Sciences, Isfahan 81746-73461, Iran
${ }^{2}$ Department of Pharmacology, Faculty of Pharmacy and Isfahan Pharmaceutical Sciences Research Center,
Isfahan University of Medical Sciences, Isfahan 81746-73461, Iran
${ }^{3}$ Department of Pharmaceutics, Faculty of Pharmacy, Tehran University of Medical Sciences, Tehran, Iran

Correspondence should be addressed to Jaleh Varshosaz, varshosaz@pharm.mui.ac.ir

Received 17 December 2011; Revised 25 February 2012; Accepted 25 February 2012

Academic Editor: Jia You Fang

Copyright (c) 2012 Jaleh Varshosaz et al. This is an open access article distributed under the Creative Commons Attribution License, which permits unrestricted use, distribution, and reproduction in any medium, provided the original work is properly cited.

\begin{abstract}
Budesonide, a potent glucocorticoid, is used for the treatment of inflammatory bowel diseases. Current available oral formulations of budesonide have low efficacy against ulcerative colitis because of the premature drug release in the upper part of the gastrointestinal tract. In this paper a $\mathrm{pH}$ - and time-controlled colon-targeted pellet-based tablet of budesonide was established. Pellet cores were prepared by extrusion-spheronization method and further coated with xanthan gum (barrier layer), Eudragit NE30D and L30D55 combination (inner layer), and Eudragit FS30 (as enteric layer) sequentially to achieve the required release profile. The coated pellets then compressed into tablets using inert tabletting granules of Cellactose or Pearlitol. Release studies, performed in simulated gastric, intestinal, and colon $\mathrm{pH}$ were used in sequence to mimic the gastrointestinal transit. The influence of formulation variables like barrier layer thickness, inner layer composition, and enteric coat thickness on drug release were investigated and the coated pellets that contained 12\% weight gain in xanthan gum layer, Eudragit L30D55 and Eudragit NE30D with a ratio of $3: 7$ in inner layer with $30 \%$ weight gain and $25 \%$ weight gain in Eudragit FS layer were found to protect the drug release in stomach and small intestine and $83.35 \pm 2.4$ of budesonide was released at $24 \mathrm{~h}$. The drug release from the tablets prepared using $40 \%$ Cellactose 80 as tableting excipient was found to be closely similar to that of uncompressed pellets.
\end{abstract}

\section{Introduction}

Controlled-release multiunit dosage forms (e.g., pellets, granules, or microparticles) are becoming more and more important on the pharmaceutical market, as they provide several advantages compared to single-unit dosage forms (e.g., tablets or capsules) [1]. With regard to the final dosage form, the multiunits can be filled into hard gelatin capsules [2] or be compressed into disintegrating tablets [3, 4]. The advantages of tableting multiunits include less difficulty in oesophageal transport, and thus a better patient compliance. Tablets can be prepared at a lower cost because of the higher production rate of tabletting process. The expensive control of capsules integrity after filling is also eliminated. In addition, tablets containing multiunits could be scored without losing the controlled release properties, which allows a more flexible dosing regimen [5].

One challenge in the production of such systems is maintaining the desired drug release after compaction as the application of compaction pressure can lead to structural changes in the film coating and consequently altered drug release [6]. The compression-induced changes in the structure of a film coating may depend on formulation factors such as mechanical properties of the film and incorporated excipients of pellets [7]. Another important parameter that should be considered is choosing of proper cushioning 
agent to prevent of undesirable fusion of coated pellets by the compression [8]. In this study, a colon delivery formulation of budesonide was designed based on $\mathrm{pH}$ and time-dependent approach where film-coated pellets were compressed into multiparticulate tablets. Budesonide, a potent glucocorticoid, is a standard drug for the localized treatment of inflammatory bowel diseases [9]. Current available oral formulations of budesonide have low efficacy against ulcerative colitis (UC) because of the premature drug release in the upper part of the gastrointestinal tract (GIT) [10]. In this study, triple-layer-coated pellets of budesonide were developed for colonic targeting. The pellets were prepared by extrusion/spheronization method and further coated sequentially with various polymers. Then they were compressed into tablets using Cellactose 80 or Pearlitol 200 granules as tabletting excipient. The expected in vitro release pattern selected for the colon targeting was no drug release in simulated gastric fluid and not more than $10 \%$ of drug release up to the end of small intestine ( $4 \mathrm{hrs)}$ and more than $80 \%$ of drug release up to 24 hrs in the simulated colon.

\section{Materials and Methods}

2.1. Materials. Budesonide was obtained as a gift sample from Astra Zeneca (UK). Eudragit FS 30 D, Eudragit NE30D, and Eudragit L30D55 were donated by Evonik Degussa Corporation (Germany). FMC (Ireland) provided the microcrystalline cellulose as Avicel PH 101 and Avicel RC581. Talc and triethyl citrate (TEC) were obtained from Kirsh Pharma (Germany); lactose monohydrate 200 and Cellactose 80 (Coprocessed lactose-cellulose-compound) were obtained from Meggle (Germany). Pearlitol 200 (direct compressible mannitol) was obtained from ROQUETTE (France). Xanthan gum was obtained from Arthur Branwell (UK). All other materials used were of analytical reagent grade and purchased from Merck Co. (Darmstadt, Germany).

2.2. Preparation of Pellets by Extrusion/Spheronization. Core pellets containing budesonide $(1.5 \% \mathrm{w} / \mathrm{w})$, Avicel $\mathrm{PH} 101$ (6\% w/w), Avicel RC581 (24\% w/w) and lactose $(68.5 \% \mathrm{w} / \mathrm{w})$ were prepared by extrusion-spheronization using model 20 extruder and model 250 spheronizer (Caleva, UK). Distilled water was used as granulation liquid. They were dried at room temperature for $24 \mathrm{~h}$. Pellets with the size range of 840 $1000 \mu \mathrm{m}$ were used for subsequent coating.

2.3. Preparation of Budesonide-Coated Pellets. Budesonide containing pellet cores were coated with various polymers (Figure 1) using a top spray fluidized bed coater (VECTOR Corporation, Marion, Iowa) at coating conditions as shown in Table 1.

2.3.1. Inner Coat. A dispersion containing $0.25 \% \mathrm{w} / \mathrm{v}$ of xanthan gum prepared by dispersing gum in $70: 30$ ethanol: water mixture containing plastisizer, triethyl citrate (TEC) ( $5 \% \mathrm{w} / \mathrm{v}$, based on amount of solvent).

Before addition of plasticizer, gum mucilage was stirred gently for a period of $10 \mathrm{~min}$ with magnetic stirrer and the dispersion was allowed to equilibrate for a period of $3 \mathrm{~h}$. The solution was allowed to stand at room temperature for $24 \mathrm{~h}$.

2.3.2. Middle Coat. Eudragit NE30D and Eudragit L30D55: the mixture of these two polymers $(9: 1,8: 2$, and $7: 3$ ratio $(\mathrm{w} / \mathrm{w}))$ was added to a beaker, placed on a magnetic stir plate and mixed with a slow agitation for a period of $1 \mathrm{~h}$. Talc, equal to $50 \%(\mathrm{w} / \mathrm{w})$ of the total dry polymer weight and TEC equal to 20\% (w/w) of Eudragit L30D55 dry polymer weight were added in a separate volume of water and dispersed via high shear mixing. The dispersion was then added to the former blend of Eudragit dispersion. The resulting dispersion had a total solid content of $15 \%$ and was allowed to mix for a further $10 \mathrm{~min}$ prior to application to the budesonide pellets.

2.3.3. Outer Coat. Eudragit FS30D aqueous dispersion was diluted twice with water before use. Talc (50\% on dry polymer weight) and TEC (10\% on dry polymer weight) were added as glidant and plasticizer, respectively. After each coating run, pellets were fluidized for a further $15 \mathrm{~min}$ before checking the weight gain and then subsequently cured. A series of coated products were produced with different film thicknesses and quantified by the total weight gain (\% TWG).

The compositions of various pellet formulations are shown in Table 2.

2.4. Tabletting of Coated Pellets. To produce multiple unit tablets, the optimized batch of coated pellets in size range of $1190-1410 \mu \mathrm{m}$ were mixed with different ratios and different proportion of the inert tabletting granules. Diluents of Cellactose or Pearlitol granules were used for formulation development. The granules were prepared using wet granulation method. Distilled water (the granulating liquid) was added to Cellactose or Pearlitol and mixed for $10 \mathrm{~min}$ to produce a wet mass of suitable consistency, which was passed through $1 \mathrm{~mm}$ diameter sieve and were dried in an oven at $50^{\circ} \mathrm{C}$. The coated budesonide pellets and inert granules were compressed into tablets using a single punch-tabletting machine fitted with round flat faced 11.6- $\mathrm{mm}$ - diameter punches and dies at $70 \mathrm{~N}$ compressions to get sufficient strength. The compositions of various tablet formulations are shown in Table 2. Magnesium stearate was used as a lubricant in all formulations (1\%).

2.5. In Vitro Release Studies for Budesonide Pellets and Tablets. The dissolution performance of the coated pellets and prepared tablets was tested using USP method 2 (rotating paddle at $\left.50 \mathrm{rpm}, 37 \pm 0.5^{\circ} \mathrm{C}, n=6\right)$. For the first two hours of the test, $0.1 \mathrm{~N} \mathrm{HCl}(\mathrm{pH} 1.2)(250 \mathrm{~mL})$ was used as the test medium. After two hours, the test medium was changed to phosphate buffer solution (PBS) pH 7.4 (250 mL) for four hours and finally to PBS pH $6.8(250 \mathrm{~mL})$ for $18 \mathrm{~h}$. In all drug release studies, 0.5 percent $(\mathrm{w} / \mathrm{v})$ of sodium lauryl sulphate was used in each dissolution medium to maintain sink conditions [11]. Samples were withdrawn from the dissolution vessels at regular intervals and the concentration of budesonide in solution was monitored by HPLC method described below [12]. All tests were done on 6 tablets of each 


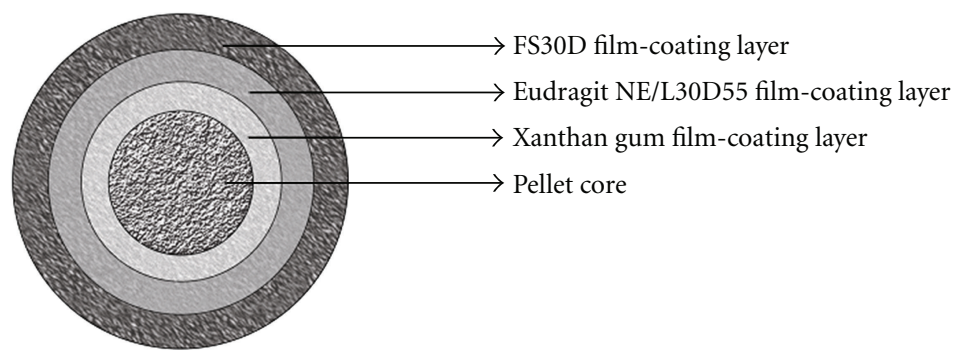

Figure 1: Schematic of the multilayer film coated pellet of Budesonide.

TABLE 1: Operating conditions for the coating experiments.

\begin{tabular}{lccc}
\hline Operating condition & Xanthan gum & Eudragit NE30D/L30D-55 & Eudragit FS 30D \\
\hline Before coating preheating to $\left({ }^{\circ} \mathrm{C}\right)$ & - & - & 1.2 \\
Coating nozzle diameter $(\mathrm{mm})$ & 0.8 & 2 & 1.2 \\
Spraying rate $(\mathrm{g} / \mathrm{min})$ & 4 & $30-32$ & 2 \\
Inlet air temperature $\left({ }^{\circ} \mathrm{C}\right)$ & 60 & $25-28$ & $35-42$ \\
Outlet air temperature $\left({ }^{\circ} \mathrm{C}\right)$ & $56-57$ & $24 \mathrm{hrs}$ at $40^{\circ} \mathrm{C}$ & $25-28$ \\
Curing on trays & $24 \mathrm{hrs}$ at $40^{\circ} \mathrm{C}$ & & $24 \mathrm{hrs}$ at $40^{\circ} \mathrm{C}$ \\
\hline
\end{tabular}

formulation and the mean of results was considered in release profiles.

2.6. Budesonide Analysis. The quantitative determination of budesonide in assay and dissolution studies was performed by HPLC method equipped with UV detector using dexamethasone as an internal standard. The analysis was carried out by using a Shimpack C8 column $(150 \mathrm{~mm} \times 4.6 \mathrm{~mm}, 5 \mathrm{~mm}$ particle size) at a wavelength of $244 \mathrm{~nm}$. The mobile phase consisted of acetonitrile, monobasic potassium phosphate $(0.025 \mathrm{M})(55: 45, \mathrm{pH}$ of 3.2$)$. The flow rate was $1.0 \mathrm{~mL} / \mathrm{min}$ and injection volume, $20 \mu \mathrm{L}$. Quantitation was achieved by measurement of the peak area ratios of the drug to the internal standard. The retention time of the budesonide chromatographic peak was found at $5 \mathrm{~min}$.

2.7. Stability Studies. Optimized formulation was kept in the humidity chamber maintained at $40^{\circ} \mathrm{C}$ and $75 \%$ relative humidity for 3 months. At the end of study, the formulation was evaluated for drug content and in vitro release profile.

2.8. Statistical Analysis. The data of drug release were analyzed using one-way analysis of variance (ANOVA). The release profiles of optimized formulation were compared in stability and reproducibility tests using model-independent approach, with the similarity factor $\left(f_{2}\right)$ defined by [13].

$$
f_{2}=50+\log \left\{\left[1+\left(\frac{1}{n}\right) \sum_{t=1}^{n} n\left(R_{t}-T_{t}\right)^{2}\right]^{-0.5} \times 100\right\} .
$$

The two release profiles were considered to be similar if $f_{2}$ value was more than 50 (between 50 and 100).

\section{Results and Discussion}

During this study, budesonide pellet core formulation was developed using extrusion-spheronization technique. These pellets were spherical in shape and showed suitable hardness to withstand coating conditions. The pellets had a $91 \pm$ $2.83 \%$ budesonide release after 2 hrs in $\mathrm{pH}$ 6.8, so any later slow release could be attributed to the coating system(s) being studied.

3.1. In Vitro Drug Release from Coated Pellets . In designing an ideal colon-targeted drug delivery system, the drug should not be released in the stomach and small intestine, and the release of drug must be completed within the residence time of the dosage form in the colon. In the case of the present study, it was assumed that for colon-targeting purpose, an $18 \mathrm{~h}$ extended release formulation with a delay in onset of about $6 \mathrm{~h}$ would be suitable. This lag time would ensure the passage of the formulation intact through the stomach and small intestine without noticeable drug loss.

The approach of using mixed polymeric coating of Eudragit NE 30D and Eudragit L30D-55 blends in time release applications has been reported previously [14]. Eudragit NE30D is an acrylic copolymer with neutral groups that enables controlled time release of the active ingredient by $\mathrm{pH}$-independent swelling [5]. As its softening temperature is $\mathrm{ca} .12^{\circ} \mathrm{C}$, it forms very flexible film suitable for compression with an elongation limit up to $300 \%$ due to the lack of strong interchain interaction [5]. Eudragit L30D-55 is an anionic polymer, which contains $\mathrm{COOH}$ as a functional group that dissolves at $\mathrm{pH}>5.5$. L30D-55 is known to be quite rigid with $20 \%$ elongation using $10 \%$ triethyl citrate as a plasticizer [15].

Four representative formulations of coated pellets were prepared by varying the ratio of Eudragit L to Eudragit NE as shown in Table 2 . The results of in vitro drug release 
TABLE 2: Formulation details of pellets and multiunit tablets.

\begin{tabular}{|c|c|c|c|c|c|}
\hline \multirow{2}{*}{$\begin{array}{l}\text { Formulation } \\
\text { code }\end{array}$} & \multirow[t]{2}{*}{ Dosage form } & \multicolumn{3}{|c|}{ Pellet composition } & \multirow{2}{*}{$\begin{array}{c}\text { Inert tabletting excipient } \\
\text { (w/w\% of tablet weight) }\end{array}$} \\
\hline & & $\begin{array}{l}\text { Barrier coat Xanthan gum } \\
(\% \text { TWG })^{*}\end{array}$ & $\begin{array}{c}\text { Inner coat L30D/NE30D } \\
\text { (ratio) }(\% \text { TWG })\end{array}$ & $\begin{array}{c}\text { Outer coat FS 30D } \\
(\% \text { TWG })\end{array}$ & \\
\hline $\mathrm{F}_{1}$ & Coated pellets & - & $(0: 10)(10)$ & - & - \\
\hline $\mathrm{F}_{2}$ & Coated pellets & - & $(0: 10)(20)$ & - & - \\
\hline $\mathrm{F}_{3}$ & Coated pellets & - & $(0: 10)(30)$ & - & - \\
\hline $\mathrm{F}_{4}$ & Coated pellets & - & $(1: 9)(30)$ & - & - \\
\hline $\mathrm{F}_{5}$ & Coated pellets & - & $(2: 8)(30)$ & - & - \\
\hline $\mathrm{F}_{6}$ & Coated pellets & - & $(3: 7)(30)$ & - & - \\
\hline $\mathrm{F}_{7}$ & Coated pellets & 2.5 & $(3: 7)(30)$ & - & - \\
\hline $\mathrm{F}_{8}$ & Coated pellets & 5 & $(3: 7)(30)$ & - & - \\
\hline $\mathrm{F}_{9}$ & Coated pellets & 10 & $(3: 7)(30)$ & - & - \\
\hline $\mathrm{F}_{10}$ & Coated pellets & 10 & $(3: 7)(30)$ & 12 & - \\
\hline $\mathrm{F}_{11}$ & Coated pellets & 10 & $(3: 7)(30)$ & 25 & - \\
\hline $\mathrm{F}_{12}$ & Multiple unit tablet & 10 & $(3: 7)(30)$ & 25 & 30 (Pearlitol) \\
\hline $\mathrm{F}_{13}$ & Multiple unit tablet & 10 & $(3: 7)(30)$ & 25 & 50 (Pearlitol) \\
\hline $\mathrm{F}_{14}$ & Multiple unit tablet & 10 & $(3: 7)(30)$ & 25 & 30 (Cellactose) \\
\hline $\mathrm{F}_{15}$ & Multiple unit tablet & 10 & $(3: 7)(30)$ & 25 & 40 (Cellactose) \\
\hline
\end{tabular}

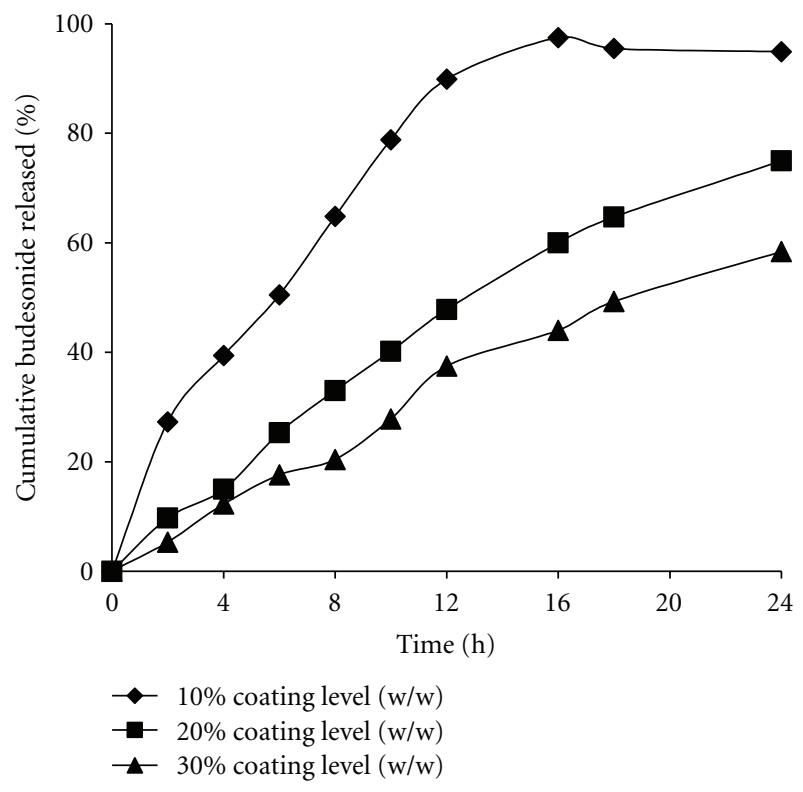

FIGURE 2: Effect of coating level of Eudragit NE 30D on budesonide release.

studies (Figure 2) indicated that increasing the polymer coating level of Eudragit NE30D from $15 \%$ to $30 \%(\mathrm{w} / \mathrm{w})$ caused a significant reduction in the drug release. The pellets coated with Eudragit NE30D at a coating level of 30\% (w/w) showed negligible release during the $6 \mathrm{~h}$ of dissolution test in $\mathrm{HCl} 0.1 \mathrm{~N}$ and PBS ( $\mathrm{pH} 7.4$ ). Nevertheless, at the end of dissolution studies, the mean percent drug released was only $58 \%$.

The effect of coating with Eudragit NE30D: Eudragit L30D-55 blend on in vitro drug release for three different

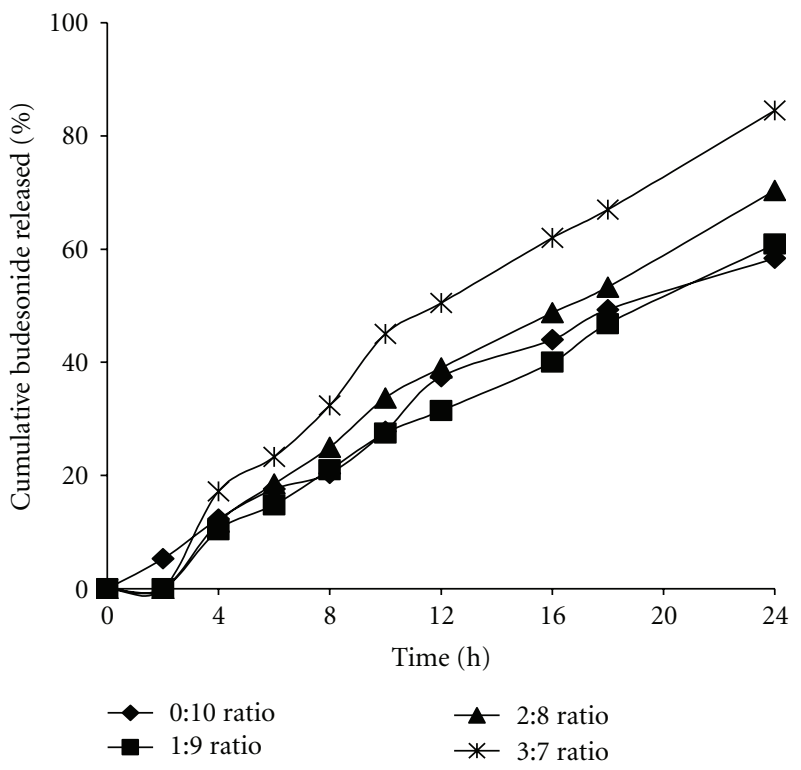

Figure 3: Effect of the ratio of Eudragit L 30D 55 to Eudragit NE 30D on budesonide release.

batches of weight gains of $30 \%(w / w)$ is shown in Figure 3. Batches $\mathrm{F}_{4}, \mathrm{~F}_{5}$, and $\mathrm{F}_{6}$ released no drug in acidic medium, $12.8 \%, 18.5 \%$, and $23.3 \%$, at the end of $6 \mathrm{hrs}$, while $57.4 \%$, $70.5 \%$, and $84.3 \%$ of drug was released at the end of 24 hrs, respectively. In PBS ( $\mathrm{pH} 7.4$ ), the enteric polymer (Eudragit L30D-55) dissolved or leached out, thus increasing the permeability of the coating, offering less resistance for budesonide diffusion. Although drug release of formulation $\mathrm{F}_{6}$ in simulating intestinal fluid was not optimal, the 3: 7 ratio of Eudragit L30D-55 to Eudragit NE30D was selected for 


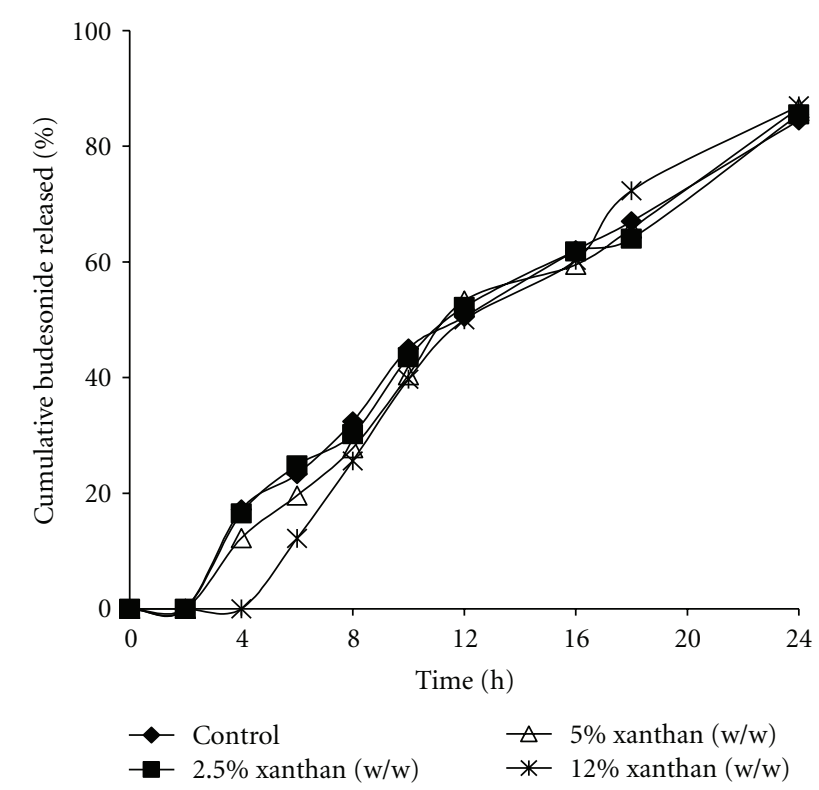

Figure 4: Budesonide release profiles from pellets with an inner coat of xanthan gum and an outer coat of Eudragit L 30D 55: Eudragit NE 30D (3:7 ratio) showing the effect of coating level of xanthan gum on budesonide release profile.

further studies in consideration of the near complete release at the end of dissolution run.

To achieve a desired release profile, a modification in the coating pattern was made. Xanthan gum as a release retardant polymer was chosen as the coating polymer for inner coating layer. Xanthan gum rapidly forms a gel layer that retards seeping of dissolution fluids into the core pellets and reduces the diffusion of drug from the core to negligible level and decreases the drug release from the formulation. Figure 4 shows the release of budesonide from pellets coated with various coating levels of xanthan gum as inner coating. Coating with $2.5 \%(\mathrm{w} / \mathrm{w})$ xanthan gum $\left(\mathrm{F}_{7}\right)$ was not sufficient, and the drug release was the same as $\mathrm{F}_{6}(P>0.05)$. However, increasing the xanthan gum coating level to $12 \%(\mathrm{w} / \mathrm{w})$ resulted in lower release in simulated intestinal fluid significantly $(P<0.05)$ with no effect on the total amount of drug released in $24 \mathrm{hrs}$.

It seems that rapid swelling and rapid erosion properties of xanthan gum played an important role in this regard. By observing the above results, it was found that $\mathrm{F}_{9}$ batch released $12.16 \pm 0.83 \%$ of the drug in the simulated intestinal fluid and released up to $84.54 \pm 0.17 \%$ at the end of the $24 \mathrm{hrs}$ in the simulated colonic medium considered as suitable batch for colon targeting. To further provids mechanical resistance and resistance against the influence of gastric juice, different coating thicknesses of Eudragit FS 30D were applied to budesonide pellets from 12 to $25 \%$ weight gain. Eudragit FS $30 \mathrm{D}$ is an anionic polymer of methacrylic acid and methacrylates that contains $-\mathrm{COOH}$ as a functional group and dissolves at $\mathrm{pH}$ 7. At the same time, FS 30D can achieve up to $300 \%$ elongation that enables decreased damage to the pellet coating during tabletting [16]. All Eudragit FS 30D

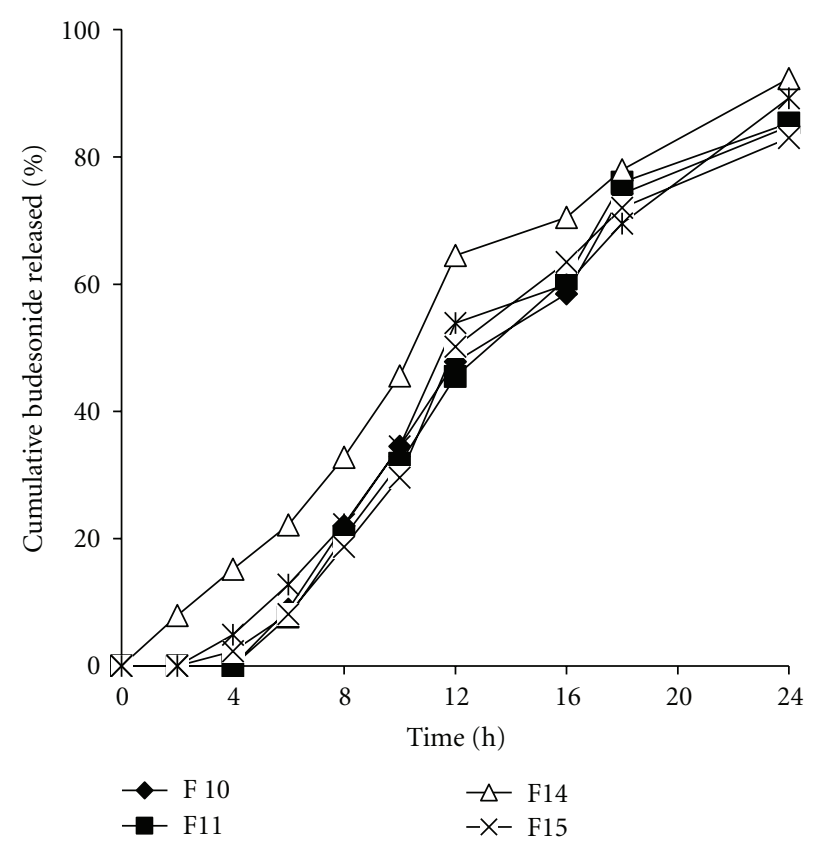

Figure 5: Release profile of selected coated pellets and multiunit tablets prepared with Cellactose in simulated GI fluid $\mathrm{pH}$.

coated pellets with $12 \%$, as well as $20 \%(\mathrm{w} / \mathrm{w})$ weight gain further suppressed budesonide release in simulated intestinal fluid but had no significant effect on total budesonide released at the end of dissolution run (Figure 5). As a thicker coating can prevent damage due to compression compared to the thinner coating and as the ability of pellets to undergo plastic and elastic deformation increases with increasing coating level [8], formulation $\mathrm{F}_{11}$ was selected to be combined with the inert tabletting granules in the preparation of multiple unit tablets.

3.2. In Vitro Drug Release from Tablets. A major problem in compaction of coated pellets is that the coating can rupture on compaction, resulting in significant differences in dissolution profiles of coated pellets prior to and after compaction. There are two approaches in pellet tabletting: tabletting of pellets without other excipients and tabletting of pellets together with pharmaceutically acceptable excipients. The approach of pellets compacting without other excipients does not have the problem of particle segregation, but formulation of pellet cores and also the coating of produced tablets is very difficult. Pellet cores must be deformable enough so that they form coherent tablets, and the coatings of pellets must be able to withstand compacting without damages, which can be ensured by formulating the coating of multiple units in such a way that the coating possesses improved elasticity. The approach of compacting of pellets together with tabletting excipients moderates requirements for the pellet coating elasticity, since plastically deformable tabletting excipients are able to partly absorb compaction forces and protect pellets from mechanical damages. This approach also enables easier obtaining of pellet-based tablets that have appropriate hardness and friability. To develop 
Table 3: Physical Characteristics of multiunit tablets of budesonide.

\begin{tabular}{lcccc}
\hline Formulation Code & Uniformity of weight $[\mathrm{mg}]$ & Hardness $[N]$ & Friability [\%] & Content uniformity \\
& RSD $\%$ & 68 & 0.72 & $2.917 \pm 11.85$ \\
\hline $\mathrm{F}_{12}$ & $448 \pm 12$ & 73 & 0.65 & $3.113 \pm 7.29$ \\
$\mathrm{~F}_{13}$ & $622.9 \pm 7.23$ & 64 & 0.14 & $3.046 \pm 3.9$ \\
$\mathrm{~F}_{14}$ & $436.9 \pm 4.28$ & 67 & 0.16 & $3.059 \pm 1.85$ \\
$\mathrm{~F}_{15}$ & $513 \pm 2.69$ & & \\
\hline
\end{tabular}

multiunit tablets of budesonide, coated pellets of $F_{11}$ batch were mixed with Cellactose or Pearlitol granules as cushioning agents and compressed. The amount of cushioning agent was modified and studied for their effect on physical parameters of tablets and dissolution. Four tablet formulations were studied $\left(F_{12}, F_{13}, F_{14}\right.$ and $\left.F_{15}\right)$ (Table 2) which were prepared at the same adjustment of press machine. Physical parameters of the tablets are shown in Table 3. All formulations were highly compressible resulting in tablets of enough crushing strength (Table 3 ). Friability of the tablets was also in the limits below $1 \%$ after $4 \mathrm{~min}$ of testing. But friability results were significantly lower with tablets $\mathrm{F}_{14}$ and $\mathrm{F}_{15}$. The results presented in Table 3 show that the content uniformity and average weight of $\mathrm{F}_{12}$ and $\mathrm{F}_{13}$ batches significantly changed during the tabletting. In contrast, the use of Cellactose produced tablets with improved content uniformity and average weight $\left(\mathrm{F}_{14}\right.$ and $F_{15}$ ). For these reasons $F_{12}$ and $F_{13}$ were excluded from further investigations. The in vitro drug release patterns of the $\mathrm{F}_{14}$ and $\mathrm{F}_{15}$ batches were compared and also compared to the pellets before compression as shown in Figure 5. In the case of batch $\mathrm{F}_{14}, 7.96 \%$ of the drug was released after $2 \mathrm{hrs}$ in gastric $\mathrm{pH}$ compared to negligible release from the pellets before compression. Then, the release became $14.32 \%$ after 4 hrs in phosphate buffer ( $\mathrm{pH} 7.4$ ), compared to $8.16 \%$ released from the pellets before compression. On the other hand, there was no difference in budesonide release from $\mathrm{F}_{15}$ and uncompressed pellets and the $f_{2}$ value was 74.85 . We conclude that the increasing concentration of Cellactose to $40 \%$ minimizes contact of multiple units with each other and protects the pellets from deformation under compression pressure.

Recently a new technique has been introduced as MMX technology for production of colon-targeted tablets. Multimatrix (MMX) technology is a promising new delivery system that can improve efficacy of current and new drugs, augmenting targeting to the affected tract, thereby increasing response and remission rates for those drugs in patients with IBD. This technology comprises hydrophilic and lipophilic excipients, enclosed within a gastroresistant, $\mathrm{pH}$-dependent coating of acrylic copolymers, which delay the release until the tablet reaches the indicated intestinal location where the programmed dissolution begins. The results of various studies involving MMX drugs have been published. Mesalamine MMX induces clinical and endoscopic remission in patients with mild-to-moderate ulcerative colitis (UC) compared with placebo. In a pilot study involving ten patients with UC, efficacy of heparin-MMX as an IBD therapy was observed.
Positive results have also been observed with MMX budesonide $9 \mathrm{mg}$ extended-release tablets in phase I studies [17]. Budesonide-MMX induced a fast and significant clinical improvement of active left-sided UC without suppression of adrenocortical functions and without important toxicity [? ]. In comparison with Budesonide-MMX tablets, the designed pellet based tablets of our study contains $3 \mathrm{mg}$ budesonide and is a pH- and time-controlled colon-targeted delivery system. In addition, tablets containing multiunits could be scored without losing the controlled release properties, which allows a more flexible dosing regimen and a more uniform spreading of the pellets through the colon.

3.3. Accelerated Stability Study. Figure 5 shows the release profiles of optimized formulation $\left(\mathrm{F}_{15}\right)$ at zero time and during storage period. No significant difference was found between the drug release profiles of the stored samples after three-month storage under accelerated conditions and $f_{2}$ was 66.4. There were no signs of visually distinguishable changes in appearance and color of pellets. The drug content was comparable with that of the control samples and within limits $( \pm 10 \%)$. On the basis of these results, it can be concluded that the formulation had enough stability under accelerated stability test conditions for three months.

\section{Conclusions}

The study discusses the formulation of colon targeted multi unit tablets of budesonide for the treatment of UC. The pellets prepared for colon targeting of drug sufficiently protected drug release in the simulated environment of stomach as well as small intestine, and majority of drug release occurred in the simulated environment of colon. The budesonide-loaded pellets coated with $12 \%(\mathrm{w} / \mathrm{w})$ xanthan gum, 30\% (w/w) mixture of Eudragit NE: Eudragit L30D55 (7: 3 ratio) and 25\% (w/w) Eudragit FS 30D exhibited a promising dissolution profile. Cellactose granules as tabletting excipient, not only produced tablets with acceptable physical parameters, but also were able to protect the coated pellets from damage during tabletting and prevent premature drug release. The developed formulations were considered stable during 3 months of storage at accelerated stability conditions. Although the proposed formulation is moderately complex, its manufacture is simple and reproducible, and could also be easily manufactured on a large-scale in a reasonable processing time using standard pharmaceutical equipments. However, it should not be forgotten that the in vitro studies of the effects of $\mathrm{pH}$ and time on the release 
characteristics are really only a prelude to in vivo studies in human volunteers and then in patients with active ulcerative colitis. It should be considered that colonic $\mathrm{pH}$ changes in the presence of active inflammation, that small bowel transit usually slows with severe colitis, and that there is often stasis in the right colon in the presence of active distal disease. Thus, in vivo data are needed to really know whether the recommended formulation is going to be relevant.

\section{References}

[1] L. F. Ali Asghar and S. Chandran, "Multiparticulate formulation approach to colon specific drug delivery: current perspectives," Journal of Pharmacy and Pharmaceutical Sciences, vol. 9, no. 3, pp. 327-338, 2006.

[2] R. Chopra, F. Podczeck, J. M. Newton, and G. Alderborn, "The influence of pellet shape and film coating on the filling of pellets into hard shell capsules," European Journal of Pharmaceutics and Biopharmaceutics, vol. 53, no. 3, pp. 327333, 2002.

[3] M. P. Flament, P. Leterme, A. Gayot, E. Gendrot, E. Bruna, and G. Cousin, "Development and industrial scale-up of tablets containing modified-release pellets," Pharmaceutical Technology Europe, vol. 6, pp. 19-25, 19994.

[4] L. Maganti and M. Çelik, "Compaction studies on pellets: II. Coated pellets," International Journal of Pharmaceutics, vol. 103, no. 1, pp. 55-67, 1994.

[5] R. Bodmeier and O. Paeratakul, "Mechanical properties of dry and wet cellulosic and acrylic films prepared from aqueous colloidal polymer dispersions used in the coating of solid dosage forms," Pharmaceutical Research, vol. 11, no. 6, pp. 882-888, 1994.

[6] A. Tunon, Preparation of tablets from reservoir pellets with an emphasis on the compression behavior and drug release, Doctoral thesis, Uppsala, Sweden, 2003.

[7] B. Ivić, S. Ibrić, G. Betz, and Z. Djurić, "Evaluation of diclofenac sodium release from matrix pellets compressed into mups tablets," Yakugaku Zasshi, vol. 129, no. 11, pp. 13751384, 2009.

[8] R. Bodmeier, “Tableting of coated pellets," European Journal of Pharmaceutics and Biopharmaceutics, vol. 43, no. 1, pp. 1-8, 1997.

[9] D. C. Baumgart, "Treatment of inflammatory bowel disease: a review of medical therapy," World Journal of Gastroenterology, vol. 33, pp. 354-377, 2008.

[10] U. Klotz and M. Schwab, "Topical delivery of therapeutic agents in the treatment of inflammatory bowel disease," Advanced Drug Delivery Reviews, vol. 57, no. 2, pp. 267-279, 2005.

[11] J. Varshosaz, J. Emami, N. Tavakoli et al., "Development of novel budesonide pellets based on CODES ${ }^{\mathrm{TM}}$ technology: in vitro/in vivo evaluation in induced colitis in rats," DARU, Journal of Pharmaceutical Sciences, vol. 19, no. 2, pp. 107-117, 2011.

[12] J. Varshosaz, J. Emami, N. Tavakoli et al., "Development and validation of a rapid HPLC method for simultaneous analysis of budesonide and its novel synthesized hemiesters in colon specific formulations," Research in Pharmaceutical Sciences, vol. 6, no. 2, pp. 107-116, 2011.

[13] D. M. Patel, R. H. Jani, and Ch. Patel, "Design and evaluation of colon targeted modified pulsincap delivery of 5-fluorouracil according to circadian rhythm," International Journal of Pharmaceutical Investigation, vol. 1, no. 3, pp. 172-181, 2011.
[14] W. Zheng and J. W. McGinity, "Influence of eudragit NE 30 D blended with eudragit L 30 D-55 on the release of phenylpropanolamine hydrochloride from coated pellets," Drug Development and Industrial Pharmacy, vol. 29, no. 3, pp. 357-366, 2003.

[15] K. G. Wagner, M. Krumme, T. E. Beckert, and P. C. Schmidt, "Development of disintegrating multiple-unit tablets on a high-speed rotary tablet press," European Journal of Pharmaceutics and Biopharmaceutics, vol. 50, no. 2, pp. 285-292, 2000.

[16] G. Fiorino, W. Fries, S. A. de la Rue, A. C. Malesci, A. Repici, and S. Danese, "New drug delivery systems in inflammatory bowel disease: MMX and tailored delivery to the gut," Current Medicinal Chemistry, vol. 17, no. 17, pp. 1851-1857, 2010.

[17] G. R. D’Haens, A. Kovács, P. Vergauwe et al., "Clinical trial: preliminary efficacy and safety study of a new budesonideMMX $9 \mathrm{mg}$ extended-release tablets in patients with active left-sided ulcerative colitis," Journal of Crohn's and Colitis, vol. 4, no. 2, pp. 153-160, 2010. 

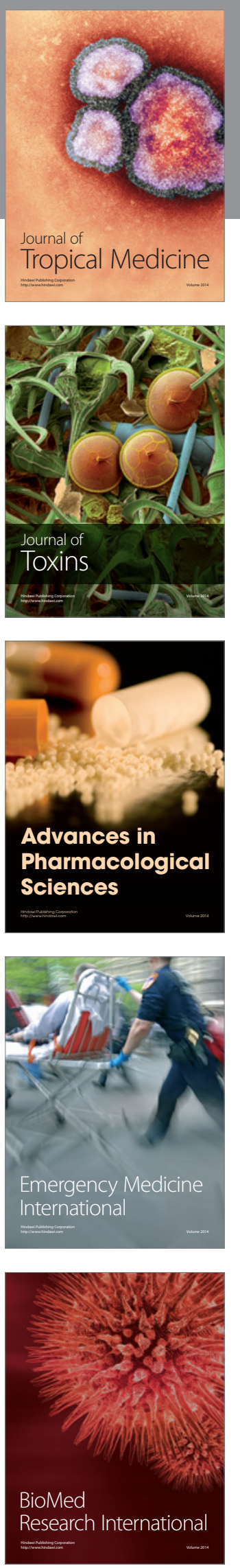
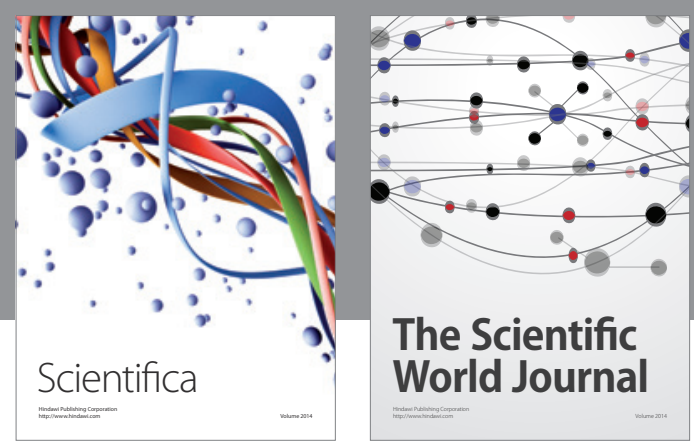

The Scientific World Journal
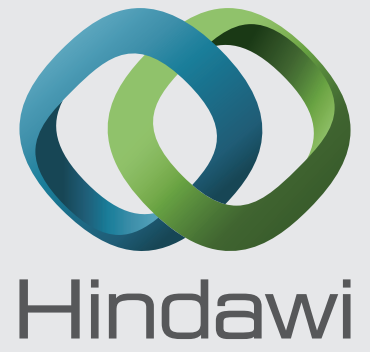

Submit your manuscripts at

http://www.hindawi.com
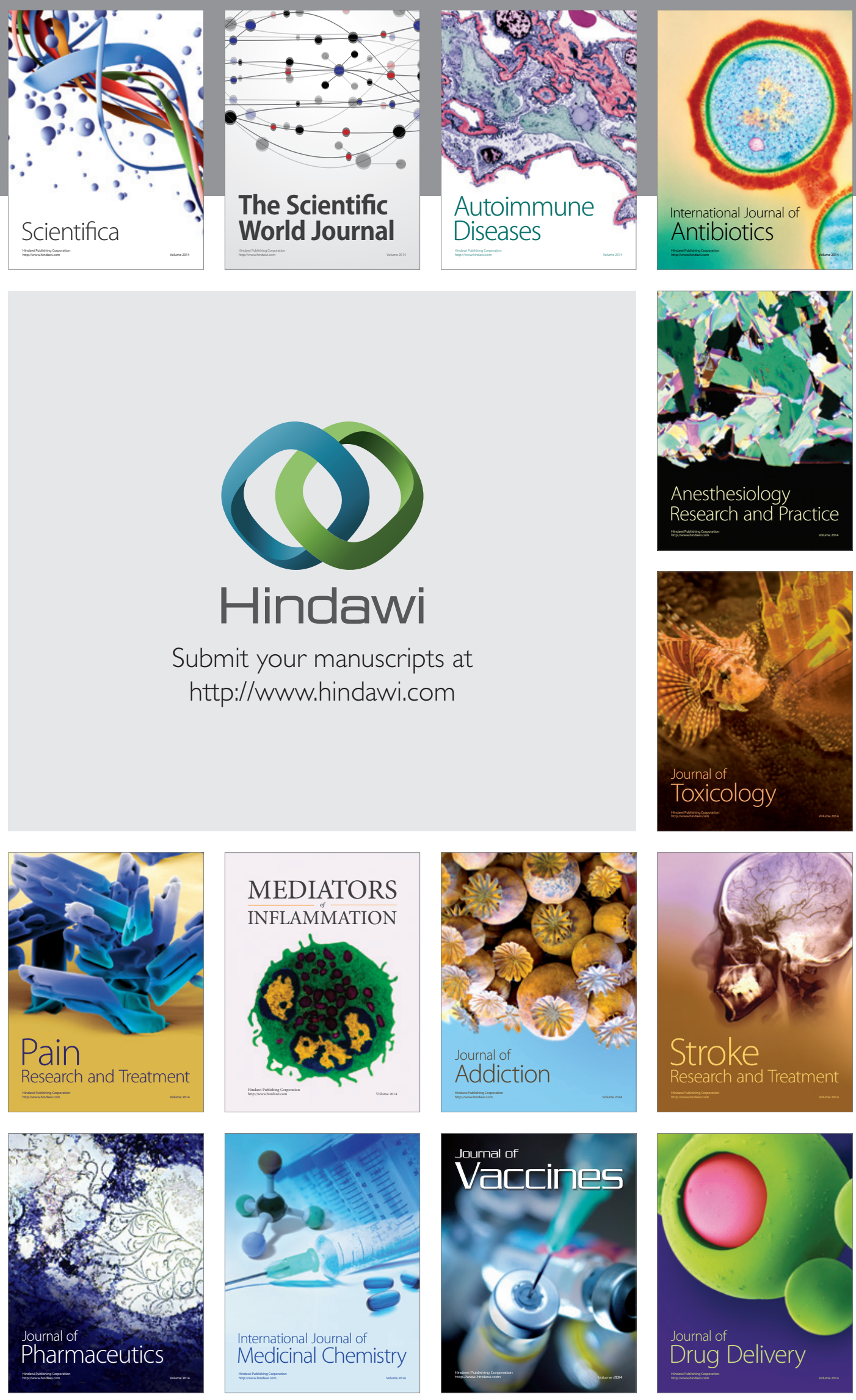